\title{
Prevalence of Cross Bite among the Orthodontic Patients at a Dental Unit of Bangladesh
}

\author{
Mohammad Sharif Hasan Chowdhury ${ }^{1}$, Naznin Sultana², Mir Abu Naim³, \\ Towhida Nashrin ${ }^{4}$, Lutfun Nahar ${ }^{5}$
}

\begin{abstract}
Assistant Professor, Department of Dentistry, Shaheed Suhrawardy Medical College, Dhaka, Bangladesh; ${ }^{2}$ Lecturer, Department of Orthodontics, Dental Unit, Rajshahi Medical College, Rajshahi, Bangladesh; ${ }^{3}$ Assistant Professor, Department of Orthodontics, Udayan Dental College, Rajshahi, Bangladesh; ${ }^{4}$ Assistant Professor, Department of Orthodontic, Update Dental College, Dhaka, Bangladesh; ${ }^{5}$ Associate Professor, Department of Orthodontic, University Dental College, Dhaka, Bangladesh.
\end{abstract}

[Received: 1 April 2019; Accepted: 15 May 2019; Published: 1 July 2019]

\begin{abstract}
Background: : Cross-bite is one of the most prevalent malocclusion. Objective: This study was an attempt to find out the prevalence of crossbite in Bangladeshi population and its variation with age and gender. Methodology: This cross-sectional study was conducted in the dental unit of Rajshahi Medical College, Rajshahi, Bangladesh from January, 2017 to December, 2018. Patients who were seeking comprehensive orthodontic treatment at the OPD of Rajshahi Medical College Dental Unit, Rajshahi, Bangladesh in between 5 to 35 years of age were diagnosed for cross-bite with diagnostic model. The findings of each cases was recorded in a preformed datasheet and the descriptive analysis was performed. Result: Out of 300 cases $163(54.3 \%)$ cases had cross-bite, 90(30\%) cases had anterior cross-bite and $109(36.3 \%)$ cases had posterior cross bite. Among posterior crossbite $60(20 \%)$ had unilateral and $49(16.3 \%)$ had bilateral crossbite. Conclusion: Posterior crossbite was more prevalent than anterior crossbite. Cases with Class I molar relation showed more crossbite. Crossbite was more prevalent in cases with congenitally missing teeth [Journal of National Institute of Neurosciences Bangladesh, 2019;5(2):167-171]
\end{abstract}

Keywords: Cross-bite; anterior cross-bite; posterior cross-bite; malocclusion; prevalence

Correspondence: Dr. Mohammad Sharif Hasan Chowdhury, Assistant Professor, Department of Dentistry, Shaheed Suhrawardy Medical College, Dhaka, Bangladesh; Email: drsharif1440@gmail.com; Cell no.: 01711427087

Conflict of interest: There is no conflict of interest relevant to this paper to disclose.

Funding agency: This research project was not funded by any group or any institution.

Contribution to authors: Chowdhury MSH, Sultana N contributed from the protocol preparation, data collection, statistical analysis up to report writing. Manuscript writing was performed by Naim MA, Towhida N, Nahar L. Chowdhury MSH involved in supervision of the research work and revision of manuscript.

How to cite this article: Chowdhury MSH, Sultana N, Naim MA, Towhida N, Nahar L. Prevalence of Cross Bite among the Orthodontic Patients at a Dental Unit of Bangladesh. J Natl Inst Neurosci Bangladesh, 2019;5(2): 167-171

Copyright: (C2019. Chowdhury et al. Published by Journal of National Institute of Neurosciences Bangladesh. This article is published under the Creative Commons CC BY-NC License (https://creativecommons.org/licenses/by-nc/4.0/). This license permits use, distribution and reproduction in any medium, provided the original work is properly cited, and is not used for commercial purposes.

\section{Introduction}

Posterior cross bite is one of the most prevalent malocclusions in the primary and early mixed dentition and is reported to occur in $8 \%$ to $22 \%$ of the cases ${ }^{1-3}$. It is defined as any abnormal buccal-lingual relation between opposing molars, premolars, or both in centric occlusion. The most common form is a unilateral presentation with a functional shift of the mandible toward the crossbite side, which occurs in $80.0 \%$ to $97.0 \%$ of cases ${ }^{3}$.

Anterior cross bite is defined as a condition where one or more teeth may be malposed abnormally, buccally or lingually with reference to the opposing tooth or tee'h4. The prevalence of Class III malocclusion in India is reported to be $3.4 \%^{4-5}$. Despite its low prevalence, it has been reported that approximately one third of orthognathic surgery comprise of this type of malocclusion ${ }^{4,6}$.

The cross bite usually involves one or two teeth, the facial profile is normal in the centric relation and in the centric occlusion. The antero-posterior skeletal relation is normal the absence of harmony at the level of dental component results from an abnormal maxillary 
inclination, either of the maxillary anterior teeth, or of the mandibular ones. This thing may be verified from a cephalometric point of view through the appreciation of the relation between the superior incisors and the ANB angle. The rest of the teeth are usually found in a neutral relation.

In a centric relation or in a posture relaxation position the patient presents a normal facial profile, In a centric relation, usually, the teeth are in relation "head to head" and the molars and distanced, but in a neutral relation and During the closing movement, an occlusion interference determines the sliding of the mandibular towards the anterior area.

In a centric relation, the profile is straight or concave. In a centric occlusion, the molar relation is of class III with anterior cross bite, Cephalometricaly the reduced or negative value of the ANB angle points out either a relative retracted maxilla or a prognathic mandible ${ }^{16}$. The etiology of posterior cross bite can include any combination of dental, skeletal, and neuro muscular functional components, but the most frequent cause is reduction in width of the maxillary dental arch. Such reduction can be induced by finger sucking ${ }^{7-9}$ certain swallowing habits ${ }^{8}$ or obstruction of the upper airways caused by adenoid tissues or nasal allergies ${ }^{9,10}$. Other etiologies of cross bites include prolonged retention or premature loss of deciduous teeth, crowding, palatal cleft, genetic control, arch deficiencies, abnormalities in tooth anatomy or eruption sequence, oral digit habits, oral respiration during critical growth periods, and malfunctioning temporomandibular joints ${ }^{11}$. Because spontaneous correction is rare ${ }^{12}$ posterior cross bite is believed to be transferred from primary to permanent dentition, with long term effects on the growth and development of the stomatognathic system ${ }^{13-14}$.

In a study by dos Santos et $\mathrm{al}^{15}$ in Brazil it was observed that $28.1 \%$ of school children has cross bite. Highest frequency was seen among 13 year old (39.3\%), followed by 14 year old $(32.0 \%)$. Regarding the type of cross bite $45.9 \%$ had unilateral cross bite, while $34.4 \%$ had anterior crossbite ${ }^{15}$. In another study by $\mathrm{Cuc}$ and $\mathrm{Cuc}^{16}$ it was observed that the frequency of cross bite is the highest between 10 to 13 years old $(5.80 \%)$, in comparison to the age group of 6 to 9 years old (4.54\%) in Brail.

Yet no significant studies have been done on the prevalence of cross bite in Bangladeshi population. This study is an attempt to find out the prevalence of cross bite in Bangladeshi population and its variation in age and gender. This study would be helpful in the diagnosis and correction of cross bite in Bangladeshi population.

\section{Methodology}

This cross-sectional study was conducted in the dental unit of Rajshahi Medical College, Rajshahi, Bangladesh from January, 2017 to December, 2018. Patients between the age of 5 years and 35 years who were seeking orthodontic treatment were included in this study. Patients with incomplete clinical record and unwilling to participate in the study were excluded. Pre-developed data sheet was used to record the findings. All the data were collected by same person. Descriptive statistics was performed for the study variables. The prevalence of cross bite among male and female was determined. Prevalence of cross bite among people with Cleft lip and palate, adenoid, mouth breathing, thumb sucking, different molar relation, congenitally missing teeth, anomaly in shape size, narrow upper arch, occlusal prematurity, delayed eruption of teeth, traumatic tooth loss and premature loss of teeth were calculated. SPSS version 17.0 for Windows was used for data analysis.

\section{Results}

The sample consisted of 300 cases attending Outpatient department of Orthodontics in Rajshahi Medical College Dental Unit, among which 99 cases were male and 201 cases were female. The age range was from 7 to 36 years with mean age of 18.33 years. Out of 300 cases $163(54.3 \%)$ cases had cross bite; $90(30 \%)$ cases had anterior cross bite and 109(36.3\%) cases had posterior cross bite. Among posterior cross bite $60(20 \%)$ cases had unilateral and $49(16.3 \%)$ cases had bilateral cross bite. Out of 54 anterior cross bite 21 was seen in male and 33 in female. $35 \%$ of cross bite in male was anterior cross bite and 32 percent of cross bite in female was anterior cross bite (Figure I \& II).

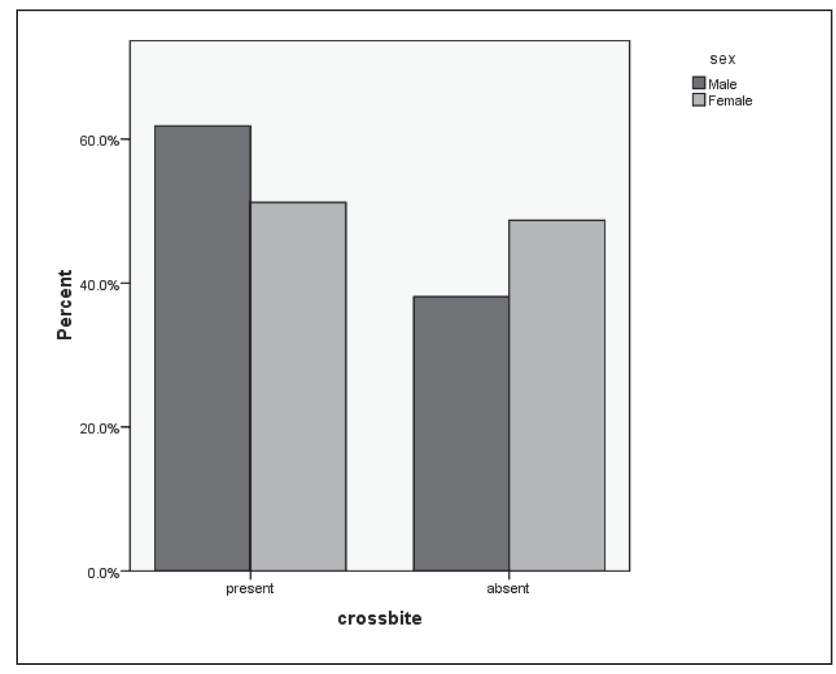

Figure I: Percentage of Male and Female with Crossbite 


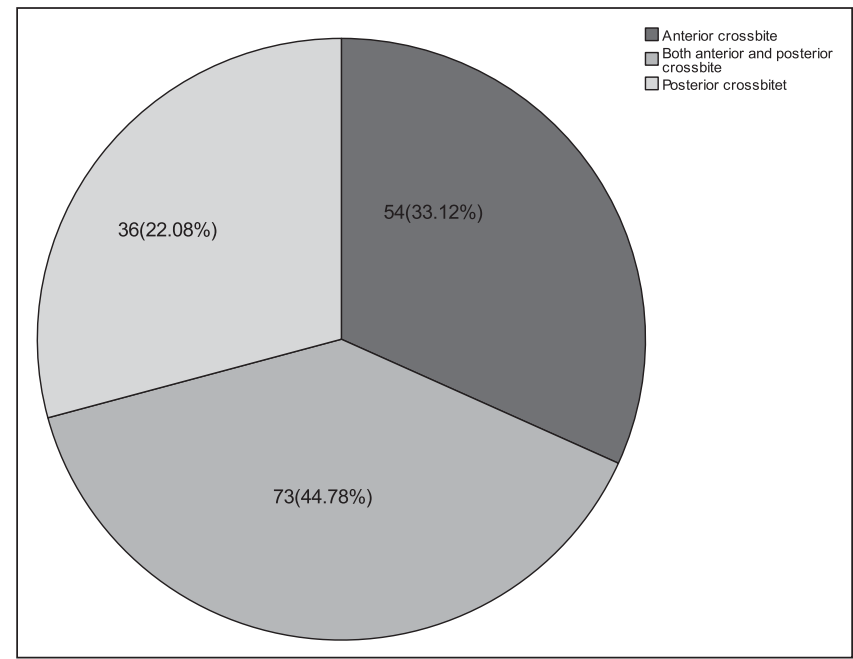

Figure I: Percentage of Male and Female with Crossbite

33.12 percent of total cross bite was anterior cross bite. 47 percent of female had posterior cross bite and 40 percent of male had posterior cross bite only. 22 percent of cases had both anterior and posterior cross bite. Crossbite, anterior crossbite, posterior crossbite, unilateral posterior crossbite and bilateral crossbite all were non-significant among male and female (Table 1).

Out of total cases we had 2 cases with missing molar and 1 among them had cross bite, 1 case of one side class II and other side Class III molar relation and 1 case of one side class I and other side Class III both had cross bite present. Out of 11 class II sub div cases 7 had cross bite. Among others Class I cases showed most number of cases with cross bite. As Class I cases were more in the study the most frequency of cross bite was noted in Class I cases. Asymmetric molar relation could be a contributing factor for cross bite (Table 2).

There were 8 cases of cleft lip and palate and all of them had cross bite, It can be concluded that cleft lip and palate was a major contributor to cross bite. Other factors like thumb sucking, family history, mouth breathing, retained deciduous tooth, congenitally missing teeth, size and shape anomaly in teeth, narrow arch, occlusal prematurity and delayed eruption can have significant influence in the development of cross bite according to the findings of this study (Table 3 ).

Table 2: Prevalence of Cross Bite in Different Molar Relation

\begin{tabular}{lcc}
\hline Different Molar Relation & Total & Cross bite \\
\hline Class I & $189(63.0 \%)$ & $99(60.73 \%)$ \\
Class II & $68(22.7 \%)$ & $30(18.40 \%)$ \\
Class III & $28(9.3 \%)$ & $24(14.72 \%)$ \\
Class II sub div & $11(3.7 \%)$ & $7(4.29 \%)$ \\
Class II and Class III & $1(0.3 \%)$ & $1(0.61 \%)$ \\
Missing Molars & $2(0.7 \%)$ & $1(0.61 \%)$ \\
Class I and Class III & $1(0.3 \%)$ & $1(0.61 \%)$ \\
Total & $\mathbf{3 0 0}(\mathbf{1 0 0 . 0 \% )}$ & $\mathbf{1 6 3}(\mathbf{1 0 0} \%)$ \\
\hline
\end{tabular}

Table 3: Prevalence of Cross Bite in Different Conditions

\begin{tabular}{lcc}
\hline Different Conditions & Frequency & Cross bite \\
\hline Cleft lip and palate & $8(2.7 \%)$ & $8(4.90 \%)$ \\
Family history & $10(3.3 \%)$ & $5(3.06 \%)$ \\
Mouth breathing & $2(0.7 \%)$ & $2(1.22 \%)$ \\
Thumb sucking & $4(1.3 \%)$ & $3(1.84 \%)$ \\
Retained deciduous & $13(4.3 \%)$ & $8(4.90 \%)$ \\
Missing teeth & $39(13.0 \%)$ & $21(12.88 \%)$ \\
Shape size anomaly & $6(2.0 \%)$ & $4(2.45 \%)$ \\
Narrow arch & $15(5.0 \%)$ & $10(6.13 \%)$ \\
Occlusal prematurity & $12(4.0 \%)$ & $9(5.52 \%)$ \\
Delayed eruption & $8(2.7 \%)$ & $7(4.29 \%)$ \\
Premature loss & $6(2.0 \%)$ & $5(3.06 \%)$ \\
Total & $\mathbf{1 2 3 ( 4 1 \% )}$ & $\mathbf{8 2}(\mathbf{5 0 . 3 0 \% )}$ \\
\hline
\end{tabular}

\section{Discussion}

Posterior crossbite occurs in $8.0 \%$ to $22.0 \%$ of orthodontic cases and anterior crossbite has been seen in Class III cases, which accounts for $3.4 \%$ of orthodontic cases. The etiology of posterior crossbite can include any combination of dental, skeletal, and neuromuscular functional components, but the most frequent cause is reduction in width of the maxillary dental arch. This study consisted of 300 cases attending the outpatient department of Orthodontic in Rajshahi

Table 1: Prevalence of Cross Bite among Male and Female

\begin{tabular}{lcccc}
\hline Variables & Male $(\mathbf{n}=\mathbf{6 0})$ & Female $(\mathbf{n}=\mathbf{1 0 3})$ & Total $(\mathbf{n = 1 6 3 )}$ & p value \\
\hline Anterior Cross bite & $21(35.0 \%)$ & $33(32.0 \%)$ & $54(33.12 \%)$ & NS \\
Both anterior and posterior & $15(25.00 \%)$ & $21(20.38 \%)$ & $36(22.08 \%)$ & NS \\
Posterior Cross bite & $24(40.00 \%)$ & $49(47.57 \%)$ & $73(44.78 \%)$ & NS \\
Unilateral Posterior Cross bite & $22(36.67 \%)$ & $28(27.18 \%)$ & $50(30.67 \%)$ & NS \\
Bilateral Posterior Cross bite & $17(28.33 \%)$ & $32(31.06 \%)$ & $49(30.00 \%)$ & NS \\
\hline
\end{tabular}


Medical College Dental Unit, out of which 201 were female and 99 were male. This clearly indicates the orthodontic awareness and concern in females than males. This is similar to the findings from other studies ${ }^{17,18}$

Out of 300 cases $163(54.3 \%)$ cases had cross bite, most of the studies have shown it to be between 8 and 22 percent ${ }^{1-3}$. The higher percentage of cross bite in this study might be because it was conducted among patients seeking orthodontic treatment and not the normal population and single tooth cross bite was also included in this study.

Crossbite, anterior crossbite, posterior crossbite, unilateral posterior crossbite and bilateral crossbite all were non-significant among male and female. This concludes that the distribution of crossbite among male and female is similar. This is similar to the result of study among school children in Brazil, among 13 to 17 age group ${ }^{19}$.

Out of total cases we had 2 cases with missing molar and 1 among them had cross bite, 1 case of one side class II and other side class III molar relation and 1 case of one side class I and other side class III both had cross bite present. Out of 11 class II sub div cases 7 had cross bite. Among others class I cases showed most number of cases with cross bite. As class I cases were more in the study the most frequency of cross bite was noted in class I cases. Asymmetric molar relation could be a contributing factor for cross bite.

There were 8 cases of cleft lip and palate and all of them had cross bite, it can be concluded that cleft lip and palate was a major contributor to cross bite. Other factors like thumb sucking, family history, mouth breathing, retained deciduous tooth, congenitally missing teeth, size and shape anomaly in teeth, narrow arch, occlusal prematurity and delayed eruption can have significant influence in the development of cross bite according to the findings of this study. This is in accordance to the findings of previous studies ${ }^{7-11}$.

Out of 54 anterior cross bite 21 was seen in male and 33 in female. $35 \%$ of cross bite in male was anterior cross bite and 32 percent of cross bite in female was anterior cross bite. 33.12 percent of total cross bite was anterior cross bite. 47 percent of female had posterior cross bite and 40 percent of male had posterior cross bite only. 22 percent of cases had both anterior and posterior cross bite. This concludes that females had more cross bite than males. This is in accordance with the study by Naeem et $\mathrm{a}^{18}$ in Pakistani population.

Crossbite, anterior crossbite, posterior crossbite, unilateral posterior crossbite and bilateral crossbite all were non-significant among male and female. This concludes that the distribution of crossbite among male and female is similar. This is similar to the result of study among school children in Brazil, among 13 to 17 age group ${ }^{19}$.

There were 8 cases of cleft lip and palate and all of them had cross bite, It can be concluded that cleft lip and palate was a major contributor to cross bite. Other factors like thumb sucking, family history, mouth breathing, retained deciduous tooth, congenitally missing teeth, size and shape anomaly in teeth, narrow arch, occlusal prematurity and delayed eruption can have significant influence in the development of cross bite according to the findings of this study. This is in accordance to the findings of previous studies ${ }^{7-11}$. Posterior cross bite was more prevalent than anterior cross bite. Cases with Class I molar relation showed more cross bite. Cross bite was more prevalent in cases with congenitally missing teeth.

\section{Conclusion}

This study concludes those females are more concern and aware of orthodontic treatment and thus the most frequency of cross bite was also seen in females. Patients with cleft lip and palate had $100.0 \%$ cross bite. There is a need to conduct this study in normal population to find out the exact prevalence of cross bite in Bangladesh. A separate study is needed to find out the prevalence of cross bite in cleft lip and palate patients with significant number of cleft lip and palate cases.

\section{References}

1. Kutin G, Hawes RR. Posterior cross-bites in the deciduous and mixed dentitions. Am J Orthod. 1969;56:491-504

2. Egermark-Eriksson I, Carlsson GE, Magnusson T, Thilander B. A longitudinal study on malocclusion in relation to signs and symptoms of cranio-mandibular disorders in children and adolescents. Eur J Orthod 1990;12:399-407

3. da Silva Andrade A, Gameiro GH, DeRossi M, Gaviao MB. Posterior Crossbite and Functional Changes-A Systematic Review. Angle Orthodontist. 2009;79(2):380-86

4. Veereshi AS, Vijayalakshmi PS. Anterior Cross Bite - An orthodontic Emergency. J Indian Dental Association 2011;5:117-119

5. Kharbanda OP, Sidhu SS, Sundaram KR, Shukla DK. Prevalence of malocclusion and its traits. J Indian Orthodontic Society 1995;26(3):98-103

6. Proffit W, White RP. Surgical Orthodontic Treatment, St Louis, Mosby, 1991, Chapter 14

7. Thilander B, Wahlund S, Lennartsson B. The effect of early interceptive treatment in children with posterior crossbite. Eur J Orthod. 1984;6:25-34

8. Melsen B, Stensgaard K, Pedersen J. Sucking habits and their influence on swallowing pattern and prevalence of malocclusion. Europ J Orthod. 1979;1:271-280 
9. Linder-Aronson S. Adenoids. Their effect on mode of breathing and nasal airflow and their relationship to characteristics of the facial skeleton and the dentition. Acta Otolaryngol.1970;265:1-132

10. Hannuksela A, Vaananen A. Predisposing factors for malocclusion in 7-year-old children with special reference to atopic diseases. Am J Orthod Dentofacial Orthop. 1987;92: 299-303

11. Allen D, Rebellato J, Sheats R, Ceron AM. Skeletal and dental contributions to posterior crossbites. The Angle Orthodontist. 2003;73(5):515-24

12. Kutin G, Hawes RR. Posterior cross-bites in the deciduous and mixed dentitions. Am J Orthod. 1969;56:491-504

13. Proffit WR. Treatment of orthodontic problems in preadolescent children (section VI). In: Proffit WR, ed. Contemporary Orthodontics. 3rd ed. St Louis, Mo: Mosby; 2000:435-439
14. McNamara JA. Early intervention in the transverse dimension: is it worth the effort? Am J Orthod Dentofacial Orthop. 2002:12:572-574

15. dos Santos JA, Cavalcanti AL, Aguiar YP. Prevalence of anterior and posterior crossbite in 13-17 year old schoolchildren attending municipal public schools in the city of Campina Grande (PB). South Brazilian Dentistry Journal. 2010;7(3):261-7

16. Cuc A, Cuc O. Reverse crossbite-statistical study in the period of mixed dentition. Analele Universitătii din Oradea, Fascicula: Ecotoxicologie, Zootehnie și Tehnologii de Industrie Alimentară. 2011;10(B):69-74.

17. Hamdan AM. The relationship between patient, parent and clinician perceived need and normative orthodontic treatment need. Eur J Orthod 2004;26:265-71

18. Naeem S, Asad S, Waheed-ul-Hamid M. Prevalence of crossbite in orthodontic patients. Pakistan Oral \& Dental Journal. 2009; 20(2):279-280 